Supporting Information for

\title{
Flow-Field-Assisted Dielectrophoretic Microchips for High-Efficiency Sheathless Particle/Cell Separation with Dual Mode
}

\author{
Shitao Shen ${ }^{1}$, Zichuan $\mathrm{Yi}^{1,2}$, Xing $\mathrm{Li}^{1}$, Shuting Xie ${ }^{1}$, Mingliang Jin ${ }^{1 *}$, Guofu Zhou ${ }^{1}$, Zhibin Yan ${ }^{1 *}$ and \\ Lingling Shui ${ }^{*}$ \\ ${ }^{1}$ International Joint Laboratory of Optofluidic Technology and System, National Center for International \\ Research on Green Optoelectronics, South China Academy of Advanced Optoelectronics and School of \\ Information and Optoelectronic Science and Engineering, South China Normal University, Guangzhou \\ 510006, China \\ ${ }^{2}$ College of Electron and Information, University of Electronic Science and Technology of China, \\ Zhongshan Institute, Zhongshan 528402, China \\ *Corresponding author: Shuill@m.scnu.edu.cn, jinml@scnu.edu.cn, zhibin.yan@m.scnu.edu.cn;
}

Tel: +86-20-3931-4813

Section 1. Dielectrophoresis theory (Table S1)

Section 2. Device fabrication process

Section 3. Sample preparation

Section 4. Drawing of the lemon electrode (Figure S1)

Section 5. Design and drawing of the arc structured channel (Figure S2)

Section 6. Design of lemon electrode array (Figure S3)

Section 7. Details of COMSOL simulation

Section 8. Contribution parameter optimization of the arc structure (Figure S4 and Figure S5)

Section 9. Particle/cell separation performance in a chip with $2 \mathrm{~cm}$ long channel (Figure S6)

Section 10. Separation of Chorella and yeast cells (Figure S7)

Section 11. Cancer cells viability (Figure S8)

Section 12. Calculation of Clausius-Mossotti factor for yeast cell and comparison table for recent advances on separation devices (Table S2 and Table S3) 


\section{Dielectrophoresis theory}

DEP can induce motion of a polarizable particle in a non-uniform E-field. ${ }^{1}$ The different polarizations for particles and surrounding medium lead to an unbalanced electric force exerted on the particles under a non-uniform E-field. The time-averaged DEP force $\left(F_{\mathrm{DEP}}\right)$ of a spherical particle is given as ${ }^{2}$

$$
\left\langle F_{\mathrm{DEP}}\right\rangle=2 \pi \varepsilon_{\mathrm{m}} R e\left[f_{\mathrm{CM}}\right] R^{3} \nabla\left|E_{\mathrm{rms}}\right|^{2},
$$

where $E_{\mathrm{rms}}$ is the mean square root (RMS) of E-field strength, and for a sine wave, the RMS value is $\sim 0.707$ times the peak value of E-field strength. ${ }^{3} \nabla\left|E_{\mathrm{rms}}\right|^{2}$ represents the gradient of the square of $E_{\mathrm{rms}}$. The parameter $\varepsilon_{\mathrm{m}}$ is the permittivity of the surrounding medium, and $R$ is the particle radius. $\operatorname{Re}\left[f_{\mathrm{CM}}\right]$ represents the real part of $f_{\mathrm{CM}}$. The parameter $f_{\mathrm{CM}}$ is the Clausius-Mossotti $(\mathrm{CM})$ factor which represents the effective polarizability as described as

$$
f_{\mathrm{CM}}=\left(\frac{\tilde{\varepsilon}_{\mathrm{p}}-\tilde{\varepsilon}_{\mathrm{m}}}{\tilde{\varepsilon}_{\mathrm{p}}+2 \tilde{\varepsilon}_{\mathrm{m}}}\right)
$$

where $\tilde{\varepsilon}_{p}$ and $\tilde{\varepsilon}_{m}$ indicate the complex permittivity of the particle and the surrounding medium, respectively. The complex permittivity responses to the angular frequency $(\omega)$ of the applied E-field, and can be written as

$$
\tilde{\varepsilon}=\varepsilon-\mathrm{j}\left(\frac{\sigma}{\omega}\right),
$$

where the real part is the permittivity, $\sigma$ is the conductivity, $j$ is the imaginary unit which can be defined as $j^{2}=-1, f$ is the frequency of the AC E-field, and the angular frequency $\omega=2 \pi f$. The numerical value of $\operatorname{Re}\left[f_{\mathrm{CM}}\right]$ ranges from -0.5 to 1 . When the particles are more polarizable than the surrounding medium $\left(\operatorname{Re}\left[f_{\mathrm{CM}}\right]>0\right)$, the particles will be attracted toward the region of the higher E-field strength by pDEP; whereas, they will be repulsed toward the region of lower E-field strength by nDEP. According to Equation (3), particles can be separated under different directions or magnitude of DEP forces due to their differences in size (i.e. diameter), permittivity or conductivity.

When suspended in a fluid, a particle is driven by the hydrodynamic drag force (Stokes force, $F_{\text {Stokes }}$ ) and DEP force at time $t$ to move at a velocity $(u)$ which can be calculated by

$$
m \frac{d u}{d t}=F_{\mathrm{DEP}}(t)-6 \pi R u \eta
$$


where $m$ is the mass of the particle, and $\eta$ is the fluid viscosity. Stokes force $\left(F_{\text {Stokes }}\right)$ has negative effect on the relative movement between particles and its surrounding fluid. When the particle's velocity is slower than the medium fluid, it is accelerated by $F_{\text {Stokes, }}$ else it is slowed down.

In this study, the characteristic dimensions of the DEP microfluidic chip are detailed in Table S1.

Table S1. Optimized dimensions of the microfluidic chip.

\begin{tabular}{ccccccccc}
\hline Dimension & $l_{1}$ & $\boldsymbol{l}_{2}$ & $l_{3}$ & $g_{1}$ & $g_{2}$ & $d_{1}$ & $d_{2}$ & $d_{3}$ \\
Value $(\mu \mathrm{m})$ & 420 & $\mathbf{1 8 0 - 2 8 0}$ & 1000 & 35 & 380 & 60 & 180 & 310 \\
\hline
\end{tabular}

\section{Device fabrication process}

Designed microchannel patterns were transferred on a SU-8 (negative photoresist) layer spin-coated on a silicon wafer (Lijing Optoelectronics Co. Ltd, Suzhou, China), to serve as master mold using the standard photolithography technique. Polydimethylsiloxane (PDMS) prepolymer and curing agent (Dow Corning Co. Midland-Michigan, USA) were mixed at a mass ratio of 10:1 and agitated by a stirring machine, and then degassed in a vacuum chamber. The mixture was then cast onto the master mold and heated at $90{ }^{\circ} \mathrm{C}$ for $0.5 \mathrm{~h}$ for curing the polymer. Afterwards, the PDMS block with designed channel patterns was peeled off from the master mould. ITO-coated glass slide was used to fabricate the electrode pattern using the standard photolithography combined with a wet-etching process. The photoresist SUN120P (Suntific Microelectronic Materials Co. Ltd, Weifang, China) was spin-coated on a clean ITO-glass (6-inch) and exposed to UV light ( $\left.365 \mathrm{~nm}, 27 \mathrm{mV} / \mathrm{cm}^{2}\right)$ for $30 \mathrm{~s}$ through a designed photomask. The photoresist coated ITO-glass was developed in a $4.0 \mathrm{wt} \% \mathrm{KOH}$ solution to remove the exposed photoresist. Afterwards, exposed ITO was etched by immersing in an aqueous solution containing $68 \%$ $\mathrm{HNO}_{3}, 37 \% \mathrm{HCL}$ and DI water at a volume ratio of 3:50:50 at $50{ }^{\circ} \mathrm{C}$, for $120 \mathrm{~s}$. Afterwards, the PDMS block with microfluidic channels and the glass with electrode patterns were treated using a plasma cleaner and then press bonded to form an integrated microfluidic chip.

Prior to the verification experiments, to mitigate internal structures adherent to the PS particles or yeast cells, the microfluidic channels were soaked with a mixture of Tween 20 and alcohol at the volume ratio of 1:4 for 5 min before running an experiment. Prior to the CTCs separation experiments, the internal structures were soaked for 5 min with $20 \%$ (wt/vol) bovine serum albumin solution to mitigate depositions of the erythrocytes and MDA-MB-231 breast cancer cells onto the microchannel wall. 


\section{Sample preparation}

To prepare yeast cell samples, $0.15 \mathrm{~g}$ of dry yeast ( $\sim 5-9 \mu \mathrm{m}$, Angel yeast Co., Ltd, China) was reactivated in $50 \mathrm{~mL}$ DI water at $35^{\circ} \mathrm{C}$ for $1 \mathrm{~h}$. Then, $2 \mathrm{~mL}$ of cultured yeast cell suspension was centrifuged at 2500 rpm for $30 \mathrm{~s}$. The supernatant was replaced by $\mathrm{KCl}$ solution $(10 \mu \mathrm{S} / \mathrm{cm})$, and measured using a conductivity meter (Alalis CD510, Alalis Instruments Technology (Shanghai) Co., Ltd, China). The centrifugation and solution replacement operations were repeated four times. For separation tests, 400 $\mu \mathrm{L}$ of $2.5 \mathrm{wt} \%$ red PS particles ( $7 \mu \mathrm{m}$, Aladdin, China) suspension was diluted with $\mathrm{KCl}$ solution (10 $\mu \mathrm{S} / \mathrm{cm})$ into $4 \mathrm{~mL}$.

The MAD-MB-231 cancer cells were washed with a solution containing $8.5 \%$ sucrose and $0.3 \%$ dextrose for three times and resuspended in DEP buffer before usage. Human erythrocytes sample was washed once and resuspended in DEP buffer before usage. For the analysis of cell viability before and after applying electric field, MAD-MB-231 cancer cells were dispersed in $36 \mu \mathrm{L}$ of DEP buffer and then placed onto the electrode with $0 \mathrm{Vpp}$ or $\mathrm{AC}$ signal of $17 \mathrm{Vpp}$ and $75 \mathrm{kHz}$ for $20 \mathrm{~s}$. The electrically treated cells were stained for 3 min with Acridine orange/ethidium bromide (AO/EB) double fluorescent solution (BBI Life Sciences Corporation, China) prepared by mixing $2 \mu \mathrm{L}$ of AO and $2 \mu \mathrm{L}$ of EB solution.

\section{Drawing of the lemon electrode}

The lemon-shaped electrode with oval hole is designed to generate electrical field gradient for dielectrophoretic (DEP) cell/particle separation. Figure S1 presents the method for drawing the lemon electrode. A Bézier curve was first drawn with four points connected in sequence, and a closed lemon shape was formed by connecting the four sections of Bézier curves (Figure S1a). Inside the lemon electrode, an oval hole was designed with $20 \mu \mathrm{m}$ off-centered at $25^{\circ}$ (Figure S1b). To avoid electrolysis on the lemon electrodes, fillet processing was used at the tips of the electrodes. 


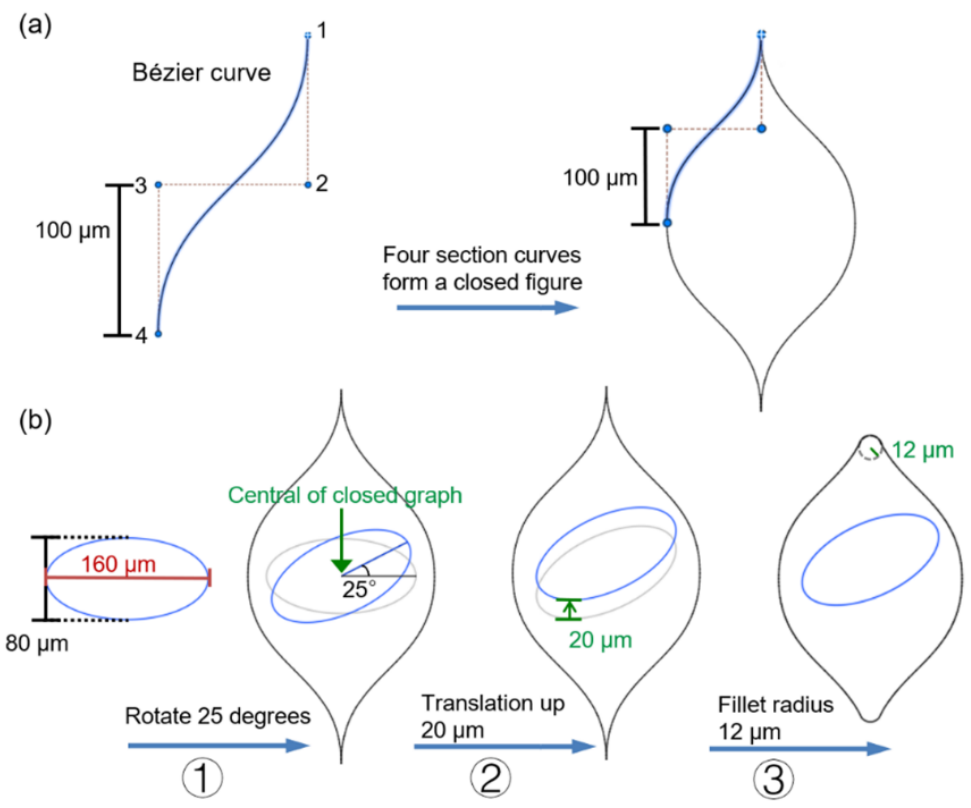

Figure S1. Schematic process for drawing the lemon electrode pattern. (a) A Bézier curve with four points is drawn as the 1/4 unit, and forming a closed lemon shape by connecting four Bézier curves. (b) An internal oval hole is created with rotation $\left(25^{\circ}\right)$ and translation $(20 \mu \mathrm{m})$, and the fillet processing is applied to the tips of the lemon electrode to prevent electrolysis.

\section{Design and drawing of the arc structured channel}

The microfluidic channel with arced structure is used to generate flow field to guide cells/particles to the position with the highest DEP field strength. The details of the arc structure design and the added fillet are shown in Figure S2. The radius of the arc structure was $110 \mu \mathrm{m}$ longer than that of $\left(l_{1}-l_{2}\right)$ (i.e. 210 $\mu \mathrm{m}$ ), which made the particles flow over the arc structure more smoothly (Figure S2a). The fillet processing for the angle formed by the arc structure and the sidewall of the channel can avoid particle aggregation due to the low local flow rate. The fillet radius was optimized by comparing the computed flow fields in the channel for three different fillet radii (Figure S2b). The optimal radius of $700 \mu \mathrm{m}$ was selected, at which the low-flow-velocity region (red circle in Figure S2b) was minimized. 


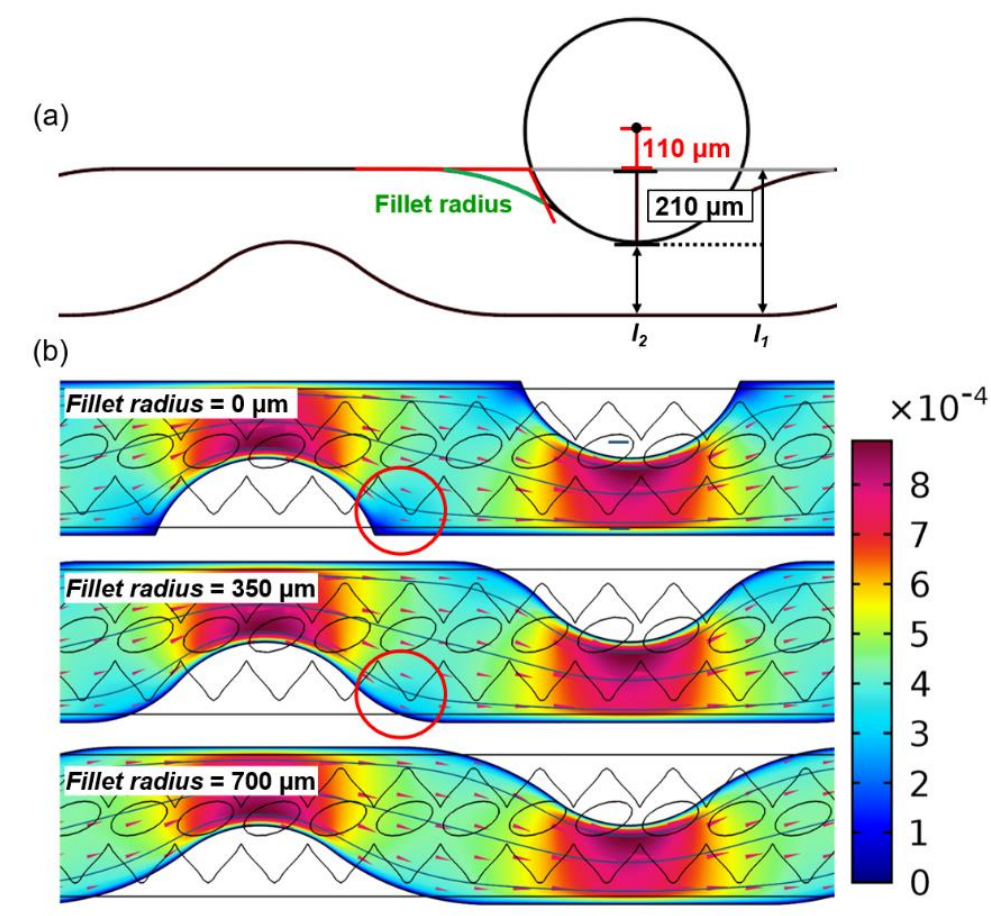

Figure S2. Design procedure of the arc structure. (a) The radius of the arc structure is $110 \mu \mathrm{m}$ longer than $\left(l_{1}-l_{2}\right)$. (b) The fillet radius was optimized at $700 \mu \mathrm{m}$ after parametric tests to avoid particles aggregation at low-flow-rate region (the red circle).

\section{Design of lemon electrode array}

To achieve sheathless separation based on DEP technique, it is necessary to generate a long-range E-field gradient normal to the continuous through flow. According to the Poisson equation, the high E-field can be generated between the electrode gap, while the low E-field produced on the center of electrode surface or inside the hole of electrode. The bipolar electrode strategy can provide two high E-field regions near two sidewalls and a low E-field region in center of channel. The high and low E-field regions provide a long-range E-field gradient which is the key factor for the generation of DEP force. Moreover, the high E-field could produce strong DEP force for separation, thus that the bipolar electrode is better than a pair of electrode design. However, to achieve high separation efficiency without prefocusing process, the electrode pattern needs to be further optimized. The theoretical foundation and key reasons for optimizing the electrode pattern were summarized as follows.

For ShLS mode, particles flow through the microfluidic channel mainly subjected to DEP force, Stokes force, buoyant force and gravitational force. Since the density of biological cells and PS particles are 
similar to that of the liquid medium, the buoyancy and gravity of particles are negligible. The major factors for particle separation are DEP force and Stokes force which directly correlate with the E-field and F-field, respectively. Here we are four key reasons for the optimization of lemon electrode design.

(1) The highest $E$ in the separation region is located around the tips of the lemon electrodes and the edges of the side electrodes, forming mountain-shaped E-field distribution (Figure 2d). At the position within $20 \mu \mathrm{m}$ near the sidewall, $E$ decreases from $\sim 8 \times 10^{4}$ to $\sim 6 \times 10^{4} \mathrm{~V} / \mathrm{m}$. Consequently, approximately $26.2 \%$ of nDEP particles cannot move from the side to the middle of the channel in the separation region without guide region design. For this reason, the guide region with the coronal edges was applied for generating an E-field gradient (Figure 2c) to guide the particles moving away from the sidewall. A short guiding distance (only $5.5 \%$ of the channel width) for the lateral moving of particles is required, thus the length of the guide region only accounts to be $1 / 10$ of the total channel length.

(2) Inside the lemon electrode array, $E$ decreases quickly from the tip to the middle of the lemon electrode indicated by the red broken line in Figure 2d. The flowing particles thus can be rapidly separated when flowing through the lemon electrode array.

(3) Outside of the lemon electrode array, in the gap area (glass covered) between the side electrode and the lemon electrode, $E$ decreases from the edge of the side electrode to the edge of lemon electrode as shown in Figure 2d (indicated by blue dot dash line). The direction of E-field gradient in the gap area is consistent with that inside the lemon electrode array. Therefore, a long-range E-field gradient normal to the continuous through-flow can be produced. The reason for designing the electrode with lemon outline is described in Figure S3.

(4) Inside the middle of each lemon electrode unit, there is an oval hole without ITO. Inside the hole, $E$ is the lowest, since there is no E-field line passing through. Moreover, due to the accumulation of charges at the edge of the oval hole, relatively higher $E$ can be induced at the edge. Hence, some pDEP particles located around the oval hole can slide along the edge. The $25^{\circ}$ tilting design of the oval hole can guide the particles toward the lemon electrode tip (Figure S3). Moreover, the lowest $E$ can also generate a concentrated region for $\mathrm{nDEP}$ particles.

To compare and optimize the shape of the lemon electrode, the electric field distributions of a diamond electrode array with the same aspect ratio of the lemon electrode array were simulated and compared as 
shown in Figure S3a. The designed lemon electrode shows higher electric field gradient near the midpoint of the Bézier curve (marked by black circle in Figure S3a), and a smaller angle with the horizontal direction of the flow field, which is more conducive to guiding the particles from the oval holes to the tips of the lemon electrodes. Figure S3b demonstrates a distinct separation of pDEP and nDEP particles in static fluid by the designed lemon electrode array with an applied AC electric field (20 Vpp and $500 \mathrm{kHz}$ ). It can be seen clearly that most of the yeast cells were concentrated near the top and bottom of the lemon electrode while a small number of yeast cells aggregated at the edge of the oval hole. Moreover, most of the red PS particles (diameter: $7 \mu \mathrm{m}$ ) are concentrated within the oval hole. Figure S3c shows the separation results of the yeast cells and red PS particles in a flowing fluid $(Q=0.6 \mu \mathrm{L} / \mathrm{min})$ by the same lemon electrode array with an applied AC electric field (20 Vpp and $500 \mathrm{kHz})$. The results verified the separation capability of the lemon electrode array with oval holes for continuous sample flow. It can be observed in Figure S3c that the red PS particles were transported near the oval holes while the yeast cells moved to the tips of the lemon electrodes. Especially, the trajectory of a yeast cell (marked by blue line) clearly shows how the designed lemon electrode with oval hole guided the yeast cell transporting from the edge of oval holes to the tips of lemon electrodes. In summary, the lemon electrode array with oval holes can provide a unique electric field gradient in the microchannel which facilitates the separation of $\mathrm{pDEP}$ and $\mathrm{nDEP}$ particles.

(a)
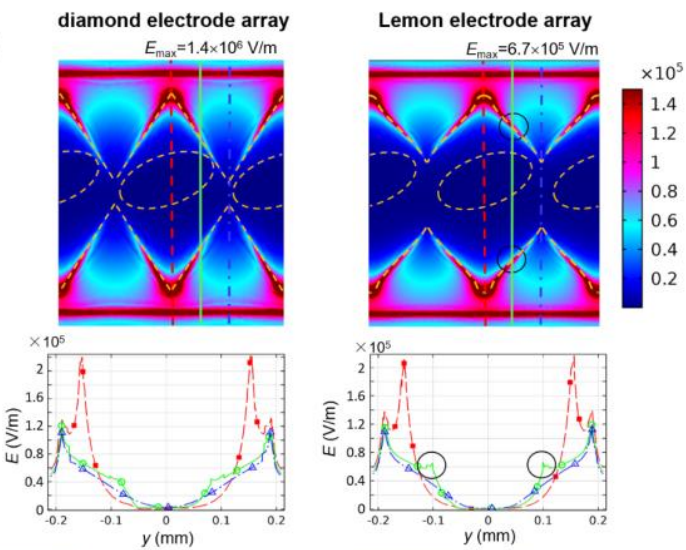

(b)
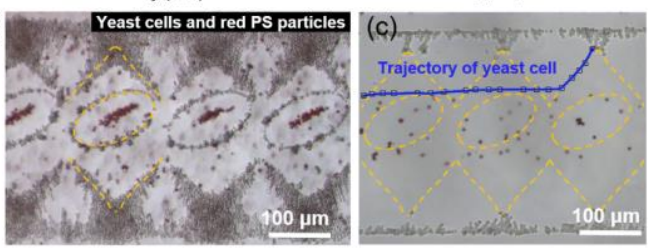

Figure S3. Comparison of the electrode designs of diamond electrodes and lemon electrodes. (a) 
Simulation results of the electric fields generated by the diamond electrodes and lemon electrodes with the same aspect ratio. The outlines of the diamond and lemon electrodes are marked using the yellow dotted lines. Separation of yeast cells and red PS particles (diameter: $7 \mu \mathrm{m}$ ) using the designed lemon electrode array in (b) a static fluid without flow and (c) a flow-field-assisted $(Q=0.6 \mu \mathrm{L} / \mathrm{min}) \mathrm{DEP}$ at an applied AC electric field (20 Vpp and $500 \mathrm{kHz}$ ). The edges of slanted oval hole can guide the yeast cells moving to the electrode tip as shown by a typical trajectory of a yeast cell (marked as blue line). The trajectory of yeast cell was obtained by analyzing the recorded video of the particle separation using the Image J Software. The positions of the moving yeast cell in each frame of the video were marked by the white squares.

\section{Details of COMSOL simulation}

A finite element simulation using electric current and laminar flow model was performed for the E-field and F-field distribution using COMSOL Multiphysics 5.5. The electric potential satisfied Poisson's equation, and the flow field distribution in microchannel was calculated by solving Navier-Stokes equation. The geometry of 3D model was built based on the optimized chip parameters as shown in Table S1. The quality of mesh consists of triangles (surface) and prisms (volume) is evaluated based on skewness. The number of elements is $1.97 \times 10^{6}$, the mesh volume is $0.1202 \mathrm{~mm}^{3}$. The boundary conditions for electric field are,

the bulk: $\nabla^{2} \phi=0, E=-\nabla \phi$;

the lemon electrode: $\phi=10 \times \cos (\omega t), \phi_{R M S}=7.07 \mathrm{~V}$;

the side electrodes: $\phi=0 \mathrm{~V}$;

the wall: $n \cdot \nabla \phi=0$.

$\phi$ is the electric potential, $\phi_{\mathrm{RMS}}$ is the mean square root (RMS) of electric potential, $E$ is the electric field, $\omega$ is the angular frequency, $t$ is time, $n$ denotes the unit normal vector pointing into electrolyte. The conductivity and relative permittivity of fluid is set of $10 \mu \mathrm{S} / \mathrm{cm}$ and 80 , respectively.

The working conditions in flow field are,

the bulk: $-\nabla p+\nabla \cdot\left(\eta\left(\nabla u+(\nabla u)^{T}\right)\right)=0, \nabla \cdot u=0$;

the wall: $u=0$.

$p$ is the hydraulic pressure, $\eta$ is the dynamic viscosity of electrolyte. The density and dynamic viscosity 
of fluid is set of $1000 \mathrm{~kg} / \mathrm{m}^{3}$ and $0.001 \mathrm{~Pa} \cdot \mathrm{s}$, respectively.

\section{Contribution parameter optimization of the arc structure}

In this experiment, the suspension containing PS particles $\left(1.4 \times 10^{7}\right.$ particles $\left./ \mathrm{mL}\right)$ and yeast cells $1.6 \times$ $10^{7}$ cells $/ \mathrm{mL}$ ) entered the guide region and randomly distributed along the channel (Figure S4a,c). In the straight channel, these particles could only be separated under DEP force (Figure S4b). Therefore, there were still many yeast cells in LFZ, flowing downstream with PS particles to lower the separation efficiency. While, in the channel with arc structures, high-efficiency separation could be achieved, as shown in Figure S4d. In the microfluidic channel with $l_{2}=210 \mu \mathrm{m}$ and $N=6$, the yeast cells reached the two side electrodes, meanwhile PS particles gathered in the middle of the channel, demonstrating that the arc structure in the chip could significantly enhance the separation efficiency.

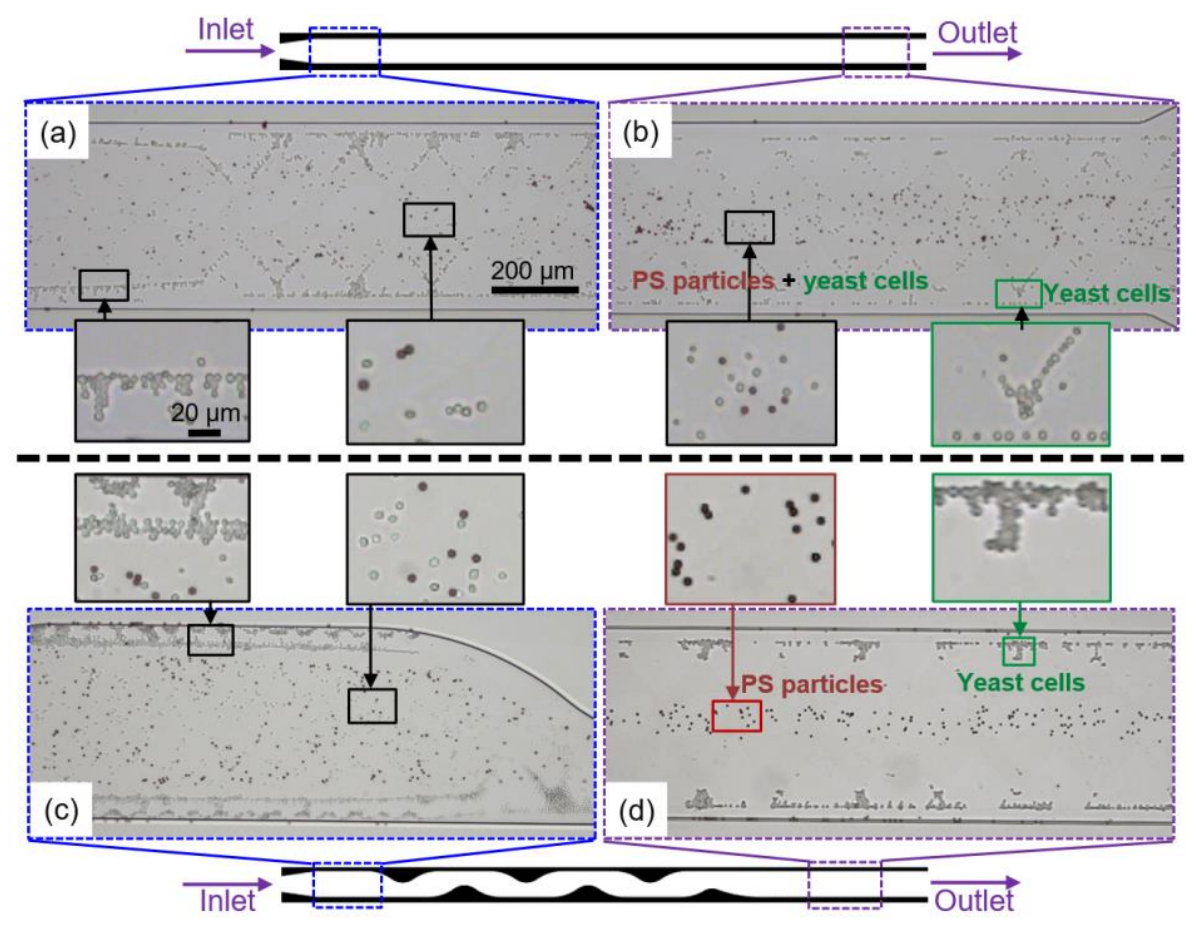

Figure S4. Comparison of the particle separation performance in a straight channel and a channel with arc structure. Photographs of (a) inlet and (b) outlet regions in a straight channel. When flowing through the separation region, the yeast cells in the middle of the channel (LFZ) are difficult to be driven to the target position. Photographs of (c) inlet and (d) outlet regions in a channel with the arc structure. By combining the effects of F-field and E-field, the yeast cells are well separated to the target position, resulting in highly efficient separation performance. The experiment was carried out 
at an applied AC signal of $20 \mathrm{Vpp}$ and $500 \mathrm{kHz}$, and $Q=0.6 \mu \mathrm{L} / \mathrm{min}$.

$l_{2}$ is one of the key parameters for the arc structure. It can significantly affect the flow field distribution in the microfluidic channel, and the maximum flow velocity when the fluid flows over the arc structure. As shown in Figure S5, the streamlines of yeast cells and PS particles around the arc structure became more concentrated with the decrease of $l_{2}$. The yeast cells are more likely to be forced to approach the edge of the channel, and stay at the edge of the channel under the trapping effect of the lemon electrode tips. However, the decreased $l_{2}$ will cause the increase of fluid velocity around the arc structure, which is inversely related to particle separation efficiency. Therefore, $210 \mu \mathrm{m}$ was selected as the optimized value of $l_{2}$ in this study.

(a)

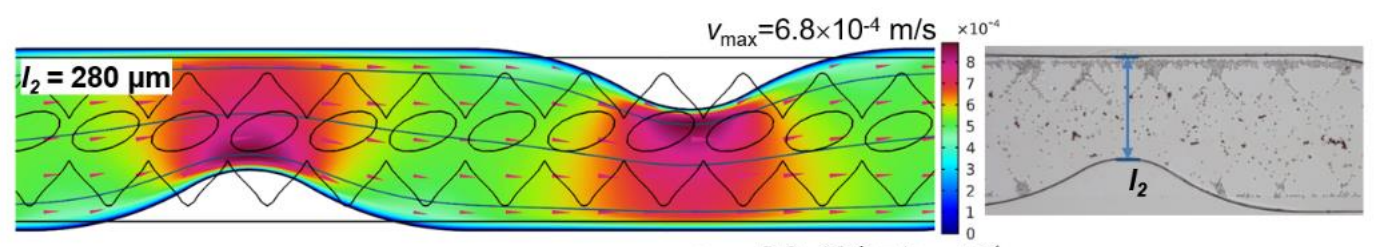

(b)

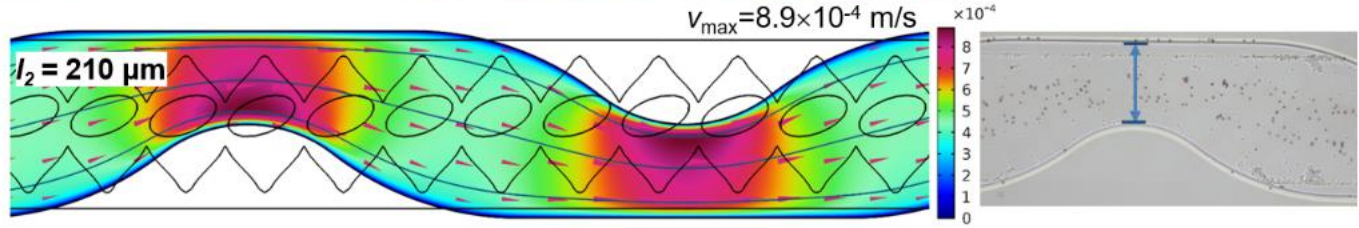

(c)

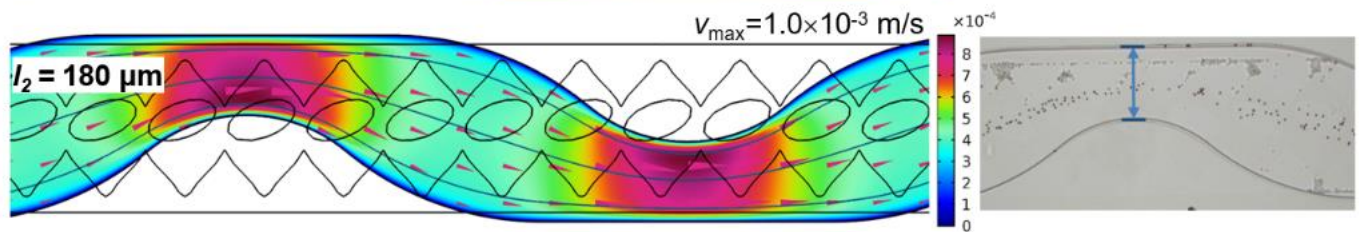

Figure S5. Optimization of $l_{2}$ for the arc structure. The simulated flow field distribution and obtained maximum flow velocity at $l_{2}$ of (a) $280 \mu \mathrm{m}$, (b) $210 \mu \mathrm{m}$, and (c) $180 \mu \mathrm{m}$. In the simulation, the microchannel is $420 \mu \mathrm{m}$ in width, $30 \mu \mathrm{m}$ in height and $1 \mathrm{~cm}$ in length. The number of the arc structure $(N)$ along the microchannel is 6 , and the pitch of the arc structure $l_{3}$ is $1000 \mu \mathrm{m}$.

\section{Particle/cell separation performance in a chip with $2 \mathrm{~cm}$ long channel}

Figure S6 shows that the particle/cell separation efficiency reduces with the increase of $Q$ for each chip design. In a chip with a short microfluidic channel, the action time of DEP force is insufficient to achieve desirable particle separation performance. To achieve a high-efficiency separation at higher $Q$, we have 
also tested a chip with $2 \mathrm{~cm}$ long channel. Figure S6a shows the separation results in downstream of a 2 cm long channel at various $Q$. As $Q$ increased, the width of the PS particle stream in the middle of the channel gradually widened, and the separation efficiency gradually decreased (Figure S6b). Compared to the purity of the yeast cell separated from PS particle suspensions using a $1 \mathrm{~cm}$ long channel $\left(l_{2}=210\right.$ $\mu \mathrm{m}$ and $N=6$ ) as illustrated in Figure 3f, the purity of the yeast cells was able to be maintained at $97.1 \%$ at $Q=1.8 \mu \mathrm{L} / \mathrm{min}$ (corresponding to the average fluid velocity of $2.59 \mathrm{~mm} / \mathrm{s}$ ) using a chip with a $2 \mathrm{~cm}$ long channel $\left(l_{2}=210 \mu \mathrm{m}\right.$ and $\left.N=16\right)$. This result indicates that the strategy of extending the channel length can improve the separation efficiency at high $Q$ using such a flow-field-assisted DEP separation chip.

(a)

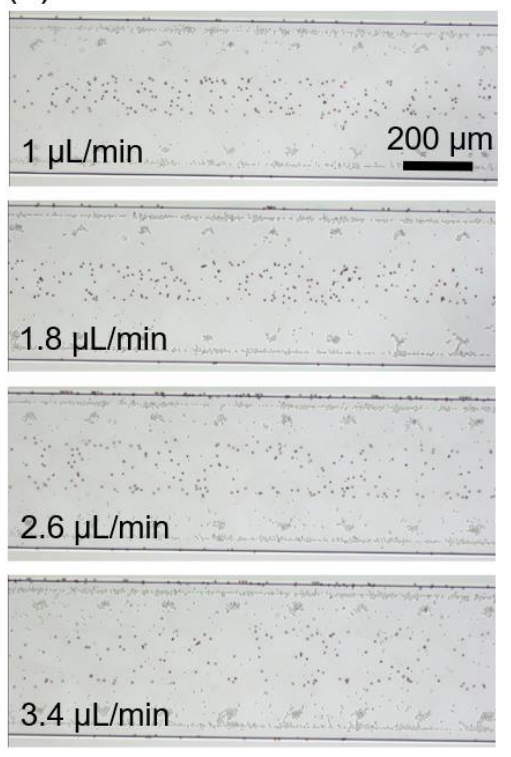

(b)

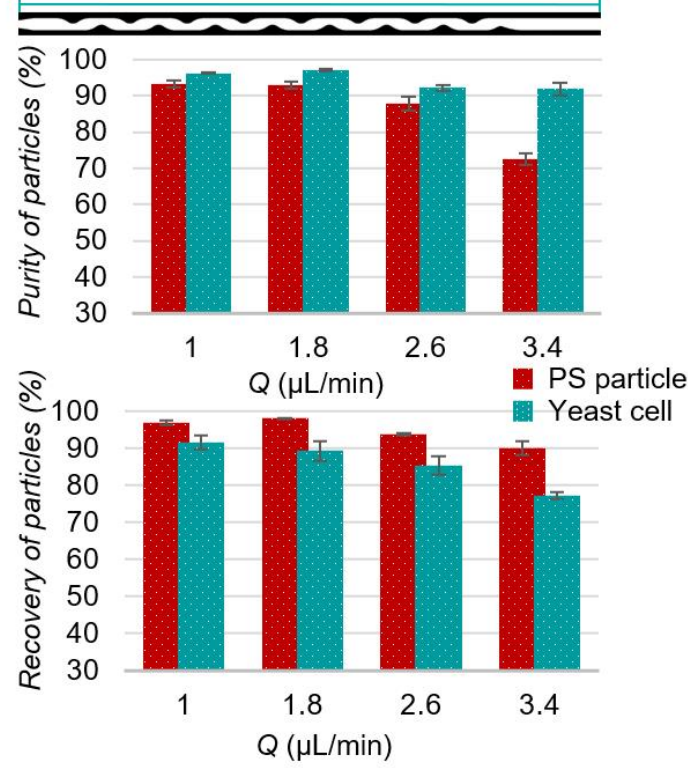

Figure S6. (a) Separation performance of the chip with a $2 \mathrm{~cm}$ long microfluidic channel $\left(l_{2}=210 \mu \mathrm{m}\right.$ and $N=16$ ) at various flow rates. (b) Purity and recovery rate of the yeast cell and PS particle after separation at various flow rates $(1 \mu \mathrm{L} / \mathrm{min}, 1.8 \mu \mathrm{L} / \mathrm{min}, 2.6 \mu \mathrm{L} / \mathrm{min}, 3.4 \mu \mathrm{L} / \mathrm{min})$.

\section{Separation of Chorella and yeast cells}

Chlorella and yeast cells exist in nutrition and affect fermentation, which have been used in aquiculture and food production fields. For instance, rotifer as fry bait can be cultured by Chlorella and yeast cells. The fatty acid composition of rotifer is deeply affected by cell types and their concentration ratio. Control purity or concentration ratio of these two types of cells can help study rotifer. To simulate the bait, the 
mixture consisting of Chlorella cells (3-8 $\mu \mathrm{m}, 5.2 \times 10^{5}$ cells/mL, Nanjing Health Biotechnology Co., Ltd.) and yeast cells $\left(1.0 \times 10^{6}\right.$ cells $\left./ \mathrm{mL}\right)$ were suspended in $\mathrm{KCl}$ solution $(240 \mu \mathrm{S} / \mathrm{cm})$, and the sheathless separation of them was achieved in the device as shown in Figure S7.

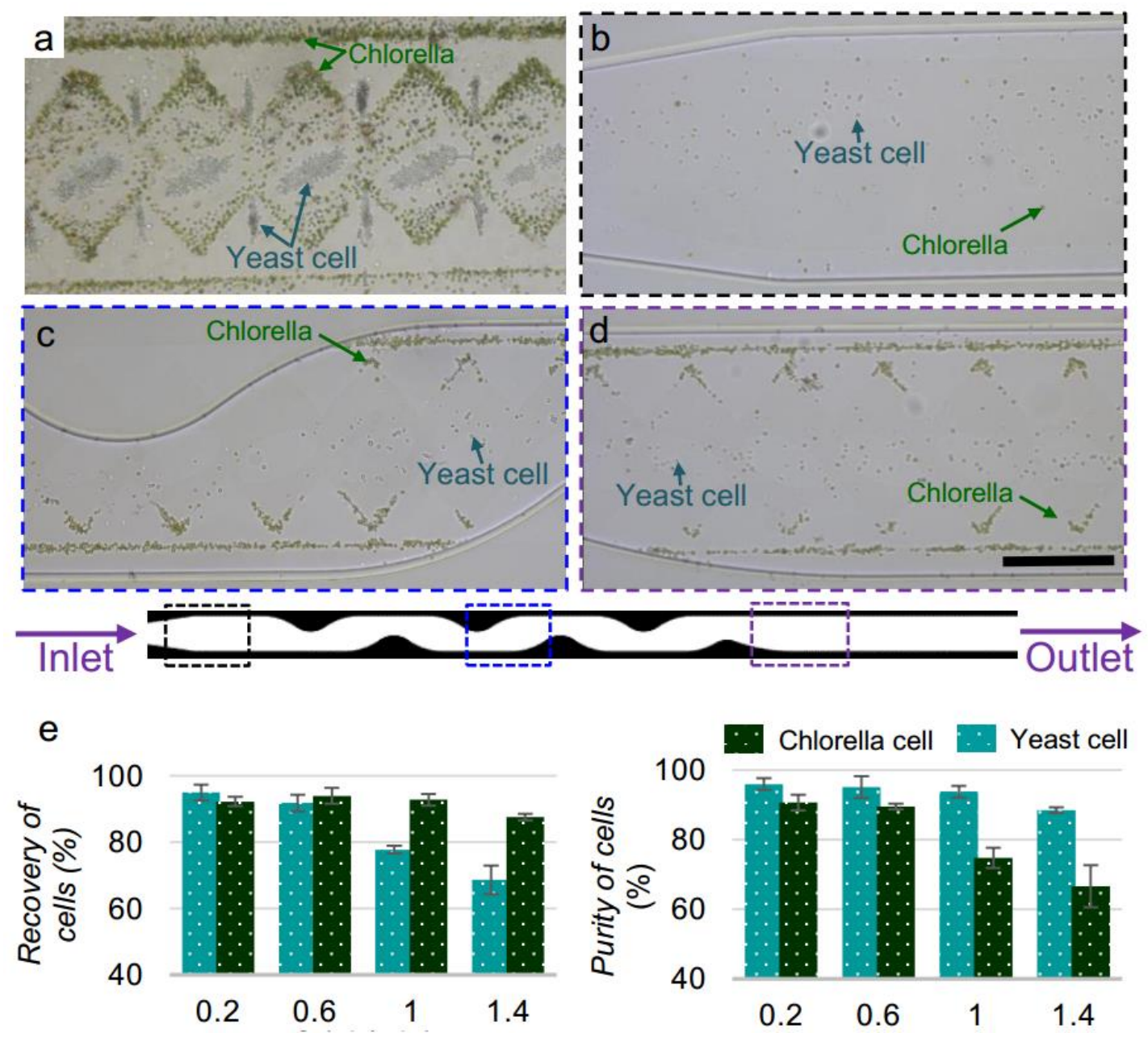

Figure S7. Separation of Chlorella cells and yeast cells in the proposed device. (a) Separation performance in static fluid. Photographs of (b) upstream, (c) midstream and (d) downstream in the optimized device at $Q=0.6 \mu \mathrm{L} / \mathrm{min}$. Scale bar is $200 \mu \mathrm{m}$. (e) Purity and recovery rate of Chlorella cells and yeast cells at various flow rates. All experiments were carried out in a $1 \mathrm{~cm}$ long channel with $N=6$ and $l_{2}=210$, at the applied AC signal of $20 \mathrm{Vpp}$ and $120 \mathrm{kHz}$.

\section{Cancer cells viability}

The cancer cells captured from outlet after applied AC electric field at $17 \mathrm{Vpp}$ and $75 \mathrm{kHz}$, were then recovered for long-term culture. The cells survived and proliferated well after 7 days culture (Figure S8). 

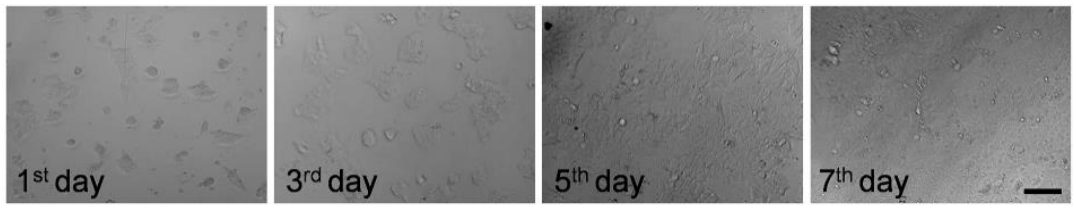

Figure S8. Optical images of the captured cancer cells after 1, 3, 5 and 7 days culture.

\section{Calculation of Clausius-Mossotti factor for yeast cell and comparison table for recent advances} on separation devices

The Clausius-Mossotti factor of yeast cells, $f_{\mathrm{CM}}$, can be calculated using a double shell model ${ }^{1}$ :

$$
\begin{aligned}
& \tilde{\varepsilon}=\varepsilon-\mathrm{j}\left(\frac{\sigma}{\omega}\right) \\
& \tilde{\varepsilon}_{\mathrm{C} \_\mathrm{mb}}=\tilde{\varepsilon}_{\mathrm{mb}} \frac{\left(\frac{r-d_{\mathrm{W}}}{r-d_{\mathrm{W}}-d_{\mathrm{mb}}}\right)^{3}+2\left(\frac{r-\tilde{\varepsilon}_{\mathrm{C}}-\tilde{\varepsilon}_{\mathrm{mb}}}{\tilde{\varepsilon}_{\mathrm{c}}+2 \tilde{\varepsilon}_{\mathrm{mb}}}\right)}{\left(\frac{r-d_{\mathrm{W}}-d_{\mathrm{mb}}}{3}\right)^{3}-\left(\frac{\tilde{\varepsilon}_{\mathrm{c}}-\tilde{\varepsilon}_{\mathrm{mb}}}{\tilde{\varepsilon}_{\mathrm{c}}+2 \tilde{\varepsilon}_{\mathrm{mb}}}\right)}
\end{aligned}
$$

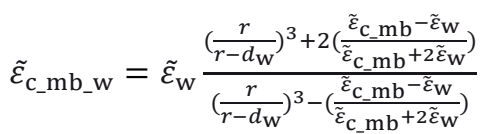

$$
\begin{aligned}
& f_{\mathrm{CM}}=\frac{\tilde{\varepsilon}_{\mathrm{c} \_\mathrm{mb} \_\mathrm{w}}-\tilde{\varepsilon}_{\mathrm{m}}}{\tilde{\varepsilon}_{\mathrm{c} \_\mathrm{mb} \_\mathrm{w}}+2 \tilde{\varepsilon}_{\mathrm{m}}}
\end{aligned}
$$

In these equations, $\tilde{\varepsilon}_{\mathrm{c}_{-} m b}$ and $\tilde{\varepsilon}_{\mathrm{c}_{-} \text {mb_w }}$ indicate the equivalent complex permittivity of homogeneous particle comprising membrane with cytoplasm and cell wall with the interior structure, respectively. Substituting the parameters in Table S2 into the formula, the value of Clausius-Mossotti factor in each frequency can be readily solved.

Table S2 Properties of the yeast cells used in the calculation ${ }^{4}$

\begin{tabular}{c|c|c}
\hline Yeast cell's radius & $r$ & $4 \mu \mathrm{m}$ \\
Cytoplasm's conductivity & $\sigma_{\mathrm{c}}$ & $0.2 \mathrm{~S} / \mathrm{m}$ \\
Cytoplasm's relative permittivity & $\varepsilon_{\mathrm{c}}$ & 50 \\
Membrane's conductivity & $\sigma_{\mathrm{mb}}$ & $2.5 \times 10^{-7} \mathrm{~S} / \mathrm{m}$ \\
Membrane's relative permittivity & $\varepsilon_{\mathrm{mb}}$ & 6 \\
Membrane's thickness & $d_{\mathrm{mb}}$ & $8 \mathrm{~nm}$ \\
\hline
\end{tabular}




\begin{tabular}{c|c|c}
\hline Cell wall's conductivity & $\sigma_{\mathrm{w}}$ & $1.4 \times 10^{-2} \mathrm{~S} / \mathrm{m}$ \\
Cell wall's relative permittivity & $\varepsilon_{\mathrm{w}}$ & 60 \\
Cell wall's thickness & $d_{\mathrm{w}}$ & $220 \mathrm{~nm}$ \\
\hline
\end{tabular}


Table S3 Recent advances on separation devices

\begin{tabular}{|c|c|c|c|c|c|c|c|c|c|}
\hline & $\begin{array}{l}\text { Prefocusing } \\
\text { method }\end{array}$ & $\begin{array}{l}\text { Prefocusing } \\
\text { requirments }\end{array}$ & $\begin{array}{l}\text { Separation } \\
\text { method }\end{array}$ & $\begin{array}{l}\text { Separation } \\
\text { critera }\end{array}$ & Sample composition & $\begin{array}{l}\text { Sample } \\
\text { flow rate } \\
(\mu \mathrm{L} / \mathrm{min})\end{array}$ & Separation efficiency & $\begin{array}{l}\text { Channel } \\
\text { length }\end{array}$ & Reference \\
\hline \multirow{4}{*}{$\begin{array}{l}\text { Passive } \\
\text { devices }\end{array}$} & Sheath flow & Syringe pump & Viscoelastic fluid & Size, shape & $\begin{array}{l}\text { Yeast Saccharomyces } \\
\text { cerevisiae with different } \\
\text { morphologies }\end{array}$ & 1 & $\begin{array}{l}\text { Clusters: recovery of } \\
\begin{array}{c}\sim 90 \% \text {, purity of } \\
35.3 \%\end{array}\end{array}$ & $1.5 \mathrm{~cm}$ & {$[5]$} \\
\hline & N/A & N/A & Viscoelastic fluid & Size, shape & $\begin{array}{c}\text { Microalgae cells and } \\
\text { bacteria }\end{array}$ & 1 & $\begin{array}{c}\text { Bacteria : Recovery of } \\
92.97 \%\end{array}$ & $>2 \mathrm{~cm}$ & [6] \\
\hline & $\begin{array}{l}\text { Inertia (zigzag } \\
\text { channel) }\end{array}$ & $\begin{array}{l}\text { Long channel } \\
\text { area }\end{array}$ & Inertia & Size, shape & $\begin{array}{l}\text { MCF-7 breast cancer cells } \\
\text { from white blood cells }\end{array}$ & 400 & $\begin{array}{c}\text { Recovery of MCF-7 } \\
\text { cells } 79.1 \%\end{array}$ & $>4.5 \mathrm{~cm}$ & [7] \\
\hline & Sheath flow & Syringe pump & $\begin{array}{l}\text { Deterministic } \\
\text { lateral } \\
\text { displacement } \\
\text { (DLD) }\end{array}$ & $\begin{array}{c}\text { Size, } \\
\text { deformability }\end{array}$ & $\begin{array}{l}\text { MDA-MB-231 cancer } \\
\text { cells from blood cells }\end{array}$ & 200 & $\begin{array}{l}90 \% \text { overall capture } \\
\text { yield, } 80 \% \\
\text { overall capture purity }\end{array}$ & $\sim 15 \mathrm{~cm}$ & [8] \\
\hline \multirow{3}{*}{$\begin{array}{l}\text { Other } \\
\text { active } \\
\text { devices }\end{array}$} & Sheath flow & Syringe pump & Magnetophoresis & $\begin{array}{c}\text { Size, magnetic } \\
\text { properties }\end{array}$ & $\begin{array}{l}\text { White blood cells from } \\
\text { mice whole blood }\end{array}$ & $\sim 10$ & Purity of $\sim 93.2$ & $\sim 3 \mathrm{~cm}$ & [9] \\
\hline & N/A & N/A & Magnetophoresis & $\begin{array}{c}\text { Size, magnetic } \\
\text { properties }\end{array}$ & $\begin{array}{l}\text { Mixture of MCF-7 and } \\
\text { MDA-MB-231 cancer } \\
\text { cells }\end{array}$ & 50 & $\begin{array}{l}\text { MCF-7 : } \sim 95.7 \%, \\
\text { MDA-MB-231 : } \\
\sim 79.3 \%\end{array}$ & $>10 \mathrm{~cm}$ & {$[10]$} \\
\hline & Sheath flow & Syringe pump & Acoustofluidics & $\begin{array}{l}\text { Size and acoustic } \\
\text { contrast factor }\end{array}$ & $\begin{array}{l}\text { MCF-7 breast cancer cells } \\
\text { from white blood cells }\end{array}$ & 20 & Recovery of $>87 \%$ & $1 \mathrm{~cm}$ & {$[11]$} \\
\hline \multirow{5}{*}{$\begin{array}{c}\text { Recent } \\
\text { sheathless } \\
\text { DEP } \\
\text { devices }\end{array}$} & Hydrophoretic & $\begin{array}{l}\text { Long channel } \\
\text { area }\end{array}$ & DEP & $\begin{array}{l}\text { Polarizability, } \\
\text { size }\end{array}$ & $\begin{array}{c}\text { Differentiated Human } \\
\text { neural stem and progenitor } \\
\text { cells }\end{array}$ & 3.5 & $\begin{array}{l}\text { Astrocyte-biased cells } \\
\text { (49\% GFAP-positive) }\end{array}$ & $>16 \mathrm{~cm}$ & [13] \\
\hline & ICEO & Signal generator & DEP & $\begin{array}{l}\text { Polarizability, } \\
\text { size }\end{array}$ & $\begin{array}{c}\text { Yeast cells from silica } \\
\text { particles }\end{array}$ & $\sim 0.13$ & Recovery: $96 \%$ & $\sim 1 \mathrm{~cm}$ & {$[14]$} \\
\hline & N/A & N/A & $\begin{array}{l}\text { DEP and AC } \\
\text { electrothermal } \\
\text { flow }\end{array}$ & Density, size & $\begin{array}{l}\text { Satellite droplets filtered } \\
\text { from parent droplets }\end{array}$ & 1.8 & $\begin{array}{l}\text { Purity of and } \\
\text { recovery }>90 \%\end{array}$ & $>0.3$ & {$[15]$} \\
\hline & N/A & N/A & DEP & $\begin{array}{l}\text { Polarizability, } \\
\text { size }\end{array}$ & $\begin{array}{c}\text { Yeast cells from PS } \\
\text { particles }\end{array}$ & 1.8 & $\begin{array}{c}\text { Recovery of } 89.4 \% \text {, } \\
\text { purity of } 97.1 \%\end{array}$ & $2 \mathrm{~cm}$ & $\begin{array}{l}\text { Present } \\
\text { work }\end{array}$ \\
\hline & N/A & N/A & DEP & $\begin{array}{c}\text { Polarizability, } \\
\text { size }\end{array}$ & $\begin{array}{l}\text { MDA-MB-231 cancer } \\
\text { cells from RBCs }\end{array}$ & 1 & $\begin{array}{c}\text { Recovery of } 89.5 \%, \\
\text { purity of } 64.2 \%\end{array}$ & $1 \mathrm{~cm}$ & $\begin{array}{l}\text { Present } \\
\text { work }\end{array}$ \\
\hline
\end{tabular}




\section{References:}

1. Jones, T. B.; Jones, T. B., Electromechanics of particles. Cambridge University Press: 2005.

2. Kirby, B. J., Micro-and nanoscale fluid mechanics: transport in microfluidic devices. Cambridge university press: 2010.

3. Ramos, A., Electrokinetics and electrohydrodynamics in microsystems. Springer Science \& Business Media: 2011; Vol. 530.

4. Lyu, C.; Wang, J.; Powell-Palm, M.; Rubinsky, B., Simultaneous electroporation and dielectrophoresis in non-electrolytic micro/nano-electroporation. Sci Rep 2018, 8 (1), 2481.

5. Liu, P.; Liu, H.; Yuan, D.; Jang, D.; Yan, S.; Li, M., Separation and Enrichment of Yeast Saccharomyces cerevisiae by Shape Using Viscoelastic Microfluidics. Analytical Chemistry 2020.

6. Yuan, D.; Zhao, Q.; Yan, S.; Tang, S.-Y.; Zhang, Y.; Yun, G.; Nguyen, N.-T.; Zhang, J.; Li, M.; Li, W., Sheathless separation of microalgae from bacteria using a simple straight channel based on viscoelastic microfluidics. Lab on a Chip 2019, 19 (17), 2811-2821.

7. Abdulla, A.; Zhang, T.; Ahmad, K. Z.; Li, S.; Lou, J.; Ding, X., Label-free Separation of Circulating Tumor Cells Using a Self-Amplified Inertial Focusing (SAIF) Microfluidic Chip. Analytical Chemistry 2020, 92 (24), 16170-16179.

8. Liu, Z.; Chen, R.; Li, Y.; Liu, J.; Wang, P.; Xia, X.; Qin, L., Integrated microfluidic chip for efficient isolation and deformability analysis of circulating tumor cells. Advanced Biosystems 2018, 2 (10), 1800200.

9. Lin, S.; Zhi, X.; Chen, D.; Xia, F.; Shen, Y.; Niu, J.; Huang, S.; Song, J.; Miao, J.; Cui, D., A flyover style microfluidic chip for highly purified magnetic cell separation. Biosensors and Bioelectronics 2019, 129, 175-181.

10. Kwak, B.; Lee, J.; Lee, D.; Lee, K.; Kwon, O.; Kang, S.; Kim, Y., Selective isolation of magnetic nanoparticle-mediated heterogeneity subpopulation of circulating tumor cells using magnetic gradient based microfluidic system. Biosensors and Bioelectronics 2017, 88, 153-158.

11. Li, P.; Mao, Z.; Peng, Z.; Zhou, L.; Chen, Y.; Huang, P.-H.; Truica, C. I.; Drabick, J. J.; El-Deiry, W. S.; Dao, M., Acoustic separation of circulating tumor cells. Proceedings of the National Academy of Sciences 2015, 112 (16), 4970-4975.

12. Urbansky, A.; Ohlsson, P.; Lenshof, A.; Garofalo, F.; Scheding, S.; Laurell, T., Rapid and effective enrichment of mononuclear cells from blood using acoustophoresis. Scientific reports 2017, 7 (1), 1-9.

13. Adams, T. N. G.; Jiang, A. Y. L.; Mendoza, N. S.; Ro, C. C.; Flanagan, L. A., Label-free enrichment of fate-biased human neural stem and progenitor cells. Biosensors \& Bioelectronics 2019, 152,111982 .

14. Chen, X.; Ren, Y.; Liu, W.; Feng, X.; Jia, Y.; Tao, Y.; Jiang, H., A simplified microfluidic device for particle separation with two consecutive steps: Induced charge electro-osmotic prefocusing and dielectrophoretic separation. Analytical chemistry 2017, 89 (17), 9583-9592.

15. Sun, H.; Ren, Y.; Hou, L.; Tao, Y.; Liu, W.; Jiang, T.; Jiang, H., Continuous particle trapping, switching, and sorting utilizing a combination of dielectrophoresis and alternating current electrothermal flow. Analytical chemistry 2019, 91 (9), 5729-5738. 